\begin{tabular}{c} 
Review of \\
ECONOMICS \\
and \\
INSTITUTIONS \\
\hline
\end{tabular}

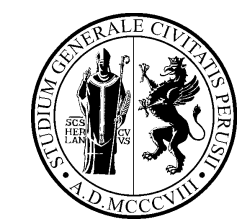

www.rei.unipg.it

\title{
Flexible Strategies for Centralized Public Procurement
}

\author{
Gian Luigi Albano \\ Head of RED, Consip
}

\author{
Marco Sparro \\ RED, Consip
}

\begin{abstract}
When designing a national public procurement system, the degree of centralization (or, equivalently, the degree of demand aggregation) is one of the most crucial as well as puzzling policy choices. Centralized procurement has been traditionally considered as an instrument to reduce public spending. In more recent years, though, and particularly after the 2008 global financial turmoil, a growing interest has arisen among both policy makers and researchers in government procurement as a lever to pursue broader policy goals, such as competitive markets structure, sustainable development and innovation. This paper reviews and discusses several issues related both to the rationales and to the practical implementation of centralized procurement strategies, with a particular focus on the procurement of goods and services.
\end{abstract}

JEL classification: H57, K12, L50, O38

Keywords: public procurement, competition, centralization, framework agreements

The current work borrows from research and teaching material drafted by the authors during the last two years. We wish to acknowledge useful comments from several audiences and, in particular, the 19th Annual IPSERA Conference at the Lappeenranta University of Technology (Finland). We are also grateful to L. Visone and $G$. Mattera at Consip's Research Unit and to an anonymous referee for constructive hints and suggestions.

\section{Why Centralizing Public Procurement Strategies?}

Cost control is definitely a key issue in public (and private) procurement. Everywhere, Governments are increasingly urged to rein back public spending. This is very often done by rationalizing public expenditure for goods and services, which account for a considerable amount of resources. Being generally perceived as "politically less

Corresponding author. Address: Consip Spa The Italian Public Procurement Agency, Via Isonzo, 19/E, 00198, Rome. (Phone:+39-06-85449627; E-mail: gianluigi.albano@tesoro.it)

\section{Recommended Citation}

Albano, G.L., Sparro, M. (2010). Flexible Strategies for Centralized Public Procurement. Review of Economics and Institutions, 1 (2), Article 4. doi: 10.5202/rei.v1i2.4. Retrieved from http://www.rei.unipg.it/rei/article/view/17 
sensitive" than pensions or health expenditure, public spending for goods and services becomes almost naturally the target of cost-controlling policies.

Demand aggregation or centralized public procurement, when appropriately designed, may help reduce purchasing costs considerably. ${ }^{1}$ This is why, all over the world, in many countries governments have resorted to a certain degree of centralization ${ }^{2}$ and charged a governmental agency with aggregating public demand and implementing centralized procurement strategies. GSA in the US, OGC and OGC Buying Solutions in the UK, PPS in Korea, ChileCompra in Chile, Hansel in Finland, BBG in Austria, Consip in Italy are just some examples of central purchasing agencies. $^{3}$

In addition, while the financial dimension remains crucial, governments agencies are usually willing to exchange better (resp., worse) financial conditions with lower (resp., higher) quality standards. Thus, it has become a commonly held view that a wider objective for public procurement - regardless of the degree of centralization - consists in the achievement of the highest possible quality-price ratio, also known as value for money.

Yet, although still quite common, this is just a narrow view of the goal(s) pursued by centralized procurement processes. In fact, the concept of value for money can be widened so as to encompass benefits accruing

\footnotetext{
${ }^{1}$ A discussion on some main rationales of centralization of procurement is carried out by Dimitri et al. (2006a).

${ }^{2}$ It is worth emphasizing that measuring and comparing the degree of centralization of public procurement in different countries is a very troublesome task, even if we restrict our attention to the value of public procurement of goods and services only. Intuitively, the degree of centralization could be easily expressed as the share of the volume of transactions realized by/via a central purchasing body (or bodies) over the total government spend in goods and services. Yet, in many countries the latter is very difficult to determine. This is due both to the organization of the state (think about federal states) and to the national accounting systems (for instance, usually public procurement expenditure covers both a fraction of the intermediate consumption and a fraction of capital investments). Moreover, one should notice that even those transactions realized by/via central purchasing bodies might not have a uniquely determined value in terms of centralization. For instance, transactions could consist of purchase orders issued under "highly centralized" framework contracts. However, they could also be generated by contracts awarded under framework agreements where the contracting authorities have large leeway of action, or by purchases autonomously made by the contracting authorities on a national e-procurement system managed by the central purchasing body. A ballpark estimate of the share of central purchasing body's transactions volume over the total government spend in goods and services would be in a range between about $5 \%$ of Italy and other EU countries with similar state structure and about $40 \%$ of South Korea.

${ }^{3}$ The relevance of centralized procurement agencies is emphasized by Carpineti et al. (2006).
} 
to the whole society rather than to the final users of the procured good/service/work only.

In this sense, it is now fairly recognized by both the academic literature and policy makers that a (centralized) procurement strategy can be employed as a powerful lever in order to target broader policy goals. A typical example is provided by the European Union, which has always considered public procurement as one of key tools to pursue a true unification of the internal market ${ }^{4}$ and, in more recent years, to reach innovation and environmental sustainability targets. ${ }^{5}$ In the US, government procurement has always played a relevant role in boosting innovation and, more recently, protecting disadvantaged social categories such as veterans, ethnical minorities, women, and small and medium enterprises (SMEs).

Another interesting example is provided by governments' reaction to face the recent financial and economic crisis. In countries whose economy is characterized by large public debts (e.g. Italy, Greece), the procurement lever has been increasingly invoked by the governments in order to control and reduce public expenditures. Conversely, countries like US and China have tackled the crisis by implementing large economic stimulus policies aimed at sustaining market demand and innovation. A relevant share of such stimulus packages heavily relies on public procurement.

To be sure, public procurement, rather than an instrument to merely control public spending, can be seen as a powerful economic and industrial policy tool. Indeed, in many sectors public demand accounts for a sizeable share of the total market demand. When this demand is aggregated, say through the action of a central purchasing agency, the central public buyer is endowed with a relevant market power and is in a position to play an important role, so as to affect the market structure, give important signal to the supply market and point the way for development and innovation.

In the next sections, we will go through an analysis of the circumstances under which centralized procurement may yield cost reduction to public administration. In doing that, though, we will not neglect to point out some mechanisms which risk to hamper the objective of spending control. In section 3, we will sketch a brief outline of some relevant fields where centralization of public procurement can play a relevant role in pursuing policies going beyond "mere" value for money or, equivalently, the concept of value for money is extended so as to embed (possibly long-run) benefits accruing to the whole society. Though, as we will see, the public

\footnotetext{
${ }^{4}$ See, for instance, European Commission (1985 and 2003).

${ }^{5}$ The two approaches, however, should be considered together as, for instance, in Monti (2010, pp. 76-78).
} 
buyer is often called to trade-off between "immediate" value for money for public contracts users and social value of procurement strategies. Section 4 will be devoted to an analysis of one major tool for the centralization of public procurement, namely the Framework Agreements. Section 5 concludes.

\section{Centralized Public Procurement and Control of Public Spending}

Carefully designed centralized procurement strategies are able to reduce the total cost of public purchases, both by achieving lower purchasing prices and by streamlining the acquisition processes, so reducing transaction cost. This is mainly due to the interaction among several forces:

- Production economies of scale and increased bargaining power of the contracting authority.

- Optimization of the procurement process via specialization, information and know-how sharing, investments in (mainly ICT) infrastructures (e-procurement tools).

\subsection{Production Economies of Scale and Bargaining Power}

The more standardized the product/service the more potentially advantageous to the buyer to aggregate demand, since suppliers are in a position to exploit economies of scale, thus operating at a lower unit cost. Economies of scale arise whenever production costs comprise a sizeable fraction of fixed costs, that is, of costs that are independent of the production scale. By increasing production firms are able to operate at a lower unit cost.

The dimension of product standardization is sometimes hard to disentangle from the degree of demand heterogeneity. To see this, consider a very simple case of procurement of gasoline. This might be considered a highly standardized commodity, but contracting authorities may differ in their preferences about delivery conditions, time of payment, physical location, consumption profiles, contract management skills, degree of freedom in budget and accounting management. Were this the case, seemingly similar procurement contracts would end up being different "objects". This implies that commodity standardization - or, better, contract standardization - should also be coupled with a low degree of demand heterogeneity for aggregation to deploy its full 
potential. ${ }^{6}$ When this is the case, demand aggregation generally allows firms to produce at a lower unit cost.

Lower production costs, however, may yield lower purchasing prices only if the buyer keeps intact or increases its bargaining power. The degree of competition is usually expected to increase with the value of procurement contracts. Particularly in markets where the public sector accounts for a relevant share of the total demand, centralization, standardization and aggregation can put the winner of a single competitive tendering in a position to significantly increase its market share. This strengthens the bargaining power of the public agency awarding the contract, so leading the suppliers to compete more fiercely to offer lower price and better quality. ${ }^{7}$

Yet, two conflicting forces come into play. For a given number of competitors, demand aggregation leads to fiercer competition. However, as the size of contracts gets larger, smaller firms may find it impossible to participate in the competitive processes - because of more demanding economic and financial requisites - thus leading to a lower number of competitors. Assuming that in most circumstances the lower participation effect is not strong enough, demand aggregation usually leads to higher savings.

\subsection{Streamline Processes, Specialization, Knowledge and Information Sharing}

Centralization also allows economies of scale to arise when setting up procurement processes. On the one hand, this is simply due to the fact that when procurement contracts are fairly homogeneous, demand aggregation avoids the duplication of "transaction costs" that would arise if each purchasing unit were to conduct the procurement process on its

\footnotetext{
${ }^{6}$ Buyers' heterogeneity can heavily hamper the effectiveness of a fully centralized procurement strategy. Alternative approaches to deal with heterogeneity are discussed in section 4. In addition, other drawbacks of demand aggregation could stem from the supply side of the market. This is discussed in section 3.1.

${ }^{7}$ It should be noticed, however, that tougher competition in the tendering process might just increase the value for money "promised" by tenderers. Yet, the effective quality of the delivered product or service and, hence, the effective value for money accruing to the buyer, also strongly depend on the buyer's contract management skills and effort. A good contract management could consist, for instance, in properly monitoring the contractor's performance, checking her compliance with the contract clauses and, where it is the case, charging the contractor with the penalties provided for in the contract. Regardless of the goodness of contract terms and conditions, an improper contract management does not provide the contractor with the right incentives to perform well. For a technical analysis of optimal procurement contracting see, for instance, Laffont and Tirole (1993) and Bolton and Dewatripont (2004). Albano et al. (2006b) provide a general, non-technical discussion on procurement contracting strategies.
} 
own and competing firms were to submit distinct offers for each procurement process. On the other hand, economies of scale also concern the overall process cost of procurement activities, as central agencies are in a position to bear the fixed cost of investments in infrastructures. A major example in this sense is provided by e-procurement tools, which typically require large investments in both hardware and software IT systems. Many central procurement agencies make available to all the contracting authorities e-procurement platforms and tools, possibly allowing them to manage all the phases of the acquisition processes (such as information collection, publication and management of competitive tendering, issuing of purchase orders). It is widely recognized that e-procurement is able to yield process cost savings as well as better value for money (for instance, from enlarged procurement market, reduced barriers to entry for the firms, improved transparency, eased data and information collection for both contracting authorities and suppliers ${ }^{8}$ ).

But some further (less frequently mentioned) factors related to centralization can lead to streamline processes. Large organizations are usually characterized by high degree of specialization of human capital while, at same time, producing lots of information. Knowledge-sharing is recognized to be a key (positive) externality arising within the boundaries of such organizations. In general, information sharing improves efficiency via the use of more up-to-date data/information, problem-sharing and common solutions. ${ }^{9}$ Moreover, seemingly different markets are often connected (e.g., printers and PCs, insurance and banking, etc.), since major competitors turn out to be multi-product firms. For instance, computer producers as Siemens, HP, IBM - as well as retailers of their products participate in procurement competitive tendering for desktop PCs but also for laptops. IBM can also bid for mainframes, data warehousing, and other IT services contracts.

Because of neighbouring markets, procurements officials would certainly benefit from information and knowledge-sharing so as to find solutions to common problems - e.g. the choice of appropriate procurement strategy, scoring rules, ${ }^{10}$ contractual arrangements. Consequently, the higher the level of centralization the more information,

\footnotetext{
${ }^{8}$ As regarding data availability, a remarkable best practice is provided by the platform of ChileCompra (Chile), which makes a large data base, including data on all the acquisitions of all the national contracting authorities, available online to all citizens.

${ }^{9}$ See section 3.2.8 in Dimitri et al. (2006b) and related references.

${ }^{10}$ Scoring rules are mathematical algorithms employed in order to score and compare different (both financial or technical) aspects of tender proposals. The design of scoring rules critically affects the incentives provided to the competitors when a contract is awarded with the most economically advantageous tender criterion. An overview of the most commonly used scoring rules is provided by Dini et al. (2006).
} 
knowledge and data can be shared among procurement specialists. This also applies to legal expertise, in that gathering qualified resources dealing with sizeable procurement processes tends to improve the clearness, transparency and measurability of the formal requirements, i.e., overall "quality" of tender documents, which in turn translates into a lower risk of legal suits.

Finally, it is important to remark that a major critical issue about centralized procurement concerns with information gathering. In fact, central purchasing bodies are usually in charge of designing and awarding large contracts to supply many (and possibly heterogeneous) public agencies. This requires a lot of information to estimate final buyers' needs and preferences, which is also crucial to reduce the degree of uncertainty faced by the firms bidding for public contracts. This task is as costly as complex, so mistakes in the demand analysis and estimation may result harmful for the procuring agencies as well as for the suppliers. The concern for demand heterogeneity will be analyzed in more details in section 4 .

\section{From Cost Control to (Social) Value for Money}

So far the discussion has provided an admittedly narrow view to the goal(s) pursued by centralized procurement processes. The ability of centralized procurement to pursue objectives laying beyond simple price reduction stems from several considerations. Firstly, public procurement policies may have a relevant impact on the market structure insofar as the award of large centralized public contracts is likely to affect the distribution of the market shares of the economic operators.

Secondly, the government is often called to deal with public goods and/or operate in markets where externalities are well known to play a crucial role. In principle, such externalities can be efficiently internalized, in the interest of the whole society, both through regulatory actions (setting of standards, rules and policies targets) or through direct management of acquisition initiatives (large government projects and investments, centralized procurement strategies).

\subsection{Effects on the Market Structure}

Aggregating public demand may have a considerable impact on firms' market shares and, consequently, on the relevant market structure. This effect is bigger the higher the share of public demand is awarded by centralized strategies. The most immediate concern relates to the potential difficulties SMEs may face in accessing the procurement market since sizeable procurement contracts would bring about more stringent 
economic requirements, thus limiting SMEs participation in centralized competitive processes. Another concern, not less worrisome, is the risk of the buyer's being locked in by a dominant supplier, which translates into a reduction of the degree of competition over time.

There exists nonetheless an attractive solution striking a balance between demand aggregation (instrumental to raise the buyer's bargaining power) and allowing participation of both large firms and SMEs, namely splitting a procurement contract into several lots and/or softening the constraints for joint bidding. ${ }^{11}$ Furthermore, if complementarities arise among different lots - say, because of sizeable common fixed costs - then allowing firms to submit package bids may become efficiency enhancing. ${ }^{12}$

The risk of lock-in refers, instead, to the repeated (i.e. dynamic) feature of public procurement. ${ }^{13}$ Indeed, there exist circumstances under which raising the degree of competition today is likely to reduce the degree of competition tomorrow. This implies that the public buyer should not only pay attention to the short run, i.e., the degree of competition in the current tender, but also at the long run, namely competition for contracts in the future. One solution to this tension is to split the procurement contract in multiple lots and to fix an upper limit to the number of lots that each firm can be awarded. Such an awarding constraint forces the number of awardees to be greater than one, so that the degree of potential competition for future contracts is preserved by giving up some competition for current contracts.

Another solution is the "split-award tendering process", 14 whereby each firm submits bids for a share of the contract as well as for a sole source award. The contract is awarded to the best offer for the whole supply (sole source) or to the combination of the two 'partial' offers (dual sourcing). The buyer may choose the solution that i) minimizes the procurement price or ii) favours either bundling or separate sales.

This procedure ensures that more than one firm has a chance to improve its technical skills while carrying out the contract. Thus, competition in future tendering processes remains relatively high. An alternative strategy to avoid lock-in is to rotate suppliers. As a consequence, several firms can improve upon their technical skills while carrying out supply contracts, which in turn maintains competition intense in the long run.

\footnotetext{
${ }^{11}$ An economic analysis of regulation of joint bidding in public procurement is carried out by Albano et al. (2009).

${ }^{12}$ For more on use of package bidding in public procurement, see Dimitri et al. (2006b).

${ }^{13}$ A compulsory reading is Lewis and Yildirim (2006) (and references therein).

${ }^{14}$ See Anton and Yao (1989).
} 


\subsection{Centralized Procurement and Innovation}

Innovation ultimately relies on production and diffusion of new knowledge, which can be seen as a public good exerting positive externalities on the whole economy. ${ }^{15}$ A simple economic argument would provide the main rationale for public intervention in the innovation market.

A discussion about the public good nature of innovation goes far beyond the scope of this work. ${ }^{16}$ Yet, it is fairly evident that almost all governments do commonly implement policies aimed at promoting innovation at different levels and through different instruments. Many of them are based on directly supporting and sustaining the "producers" of innovation ("market push" approach): from infrastructures building (say national high education systems) to subsidies to R\&D activities.

On the other hand, innovation can also be boosted by acting on the demand side of the market ("market-pull" approach). In this sense the public demand, if managed through strategic public procurement strategies, can play an important role insofar as large-scale government purchases can be oriented toward goods with different $R \& D$ content. For instance, the crucial role of US defense acquisitions in triggering or boosting innovation in sectors like transports, ICT, electronics, new materials is widely recognized. ${ }^{17}$

The major advantage of the "market-pull" approach is that it requires less information than the "market-push" one. In the economic literature, such ideas have been outlined, for instance, by Geroski (1990), Dalpé (1994) and Edler and Georghiou (2007). All of them emphasize how the effectiveness of a demand-based approach to innovation policy stems from several facts. First, procurement initiatives can make R\&D projects to be driven by actual and clearly defined needs of the government. As a consequence, procurement-based innovation policies can target the results of the R\&D activity from the final user's perspective, rather than through an "external" evaluation of technical or scientific achievements. Secondly, public demand, especially when aggregated, is able to provide those firms developing new products and processes with an assured market whose size may be as relevant as to cover the risk of large investments typically related with R\&D. Thirdly, it has been noticed that, in many cases, the creation of a public market for new products can trigger a "flywheel

\footnotetext{
${ }^{15}$ This idea dates back at least to Arrow (1962).

${ }^{16}$ More detailed discussion and further references on the relationship between procurement and innovation are presented by Cabral et al. (2006) or Edler et al. (2005). Scotchmer (2004) provides a discussion on the economics of innovation. For a critique of the view of knowledge as a public good, see Boldrin and Levine (2005).

${ }^{17}$ More examples and related references are provided by Cabral et al. (2006). The EU Project OMC-PTP (2009) provides a list of cases on recent experiences in the EU.
} 
effect" for the rise of a private market. This spillover effect is relevant, in particular, for markets characterized by "network effects", i.e. markets for products whose value for customers increases with the number of their users. ${ }^{18}$ Finally, even beyond stimulating production of innovative goods, the public sector is in a position to set forward (or even switch) the dominant standard for commonly used products and processes.

\subsubsection{Procurement of Innovation}

In recent years, the European Commission (EC) has identified the direct procurement of innovation, say in the form of R\&D projects, as "a missing link" in the European production chain of innovation, especially in comparison with the US. The direct acquisition of innovative solutions is also known as pre-commercial procurement. ${ }^{19}$

In invoking a more intensive strategic use of pre-commercial (public) procurement, the $\mathrm{EC}$ has pointed out that the acquisition of $\mathrm{R} \& \mathrm{D}$ projects lays outside of the scope of the Directive with the exception of cases where "the benefits accrue exclusively to the contracting authority for its use in the conduct of its own affairs, on condition that the service provided is wholly remunerated by the contracting authority".$^{20}$ Needless to say, such a constraint is likely to restrain the European public agencies from direct acquisition of innovation, insofar as it prevents firms from commercial exploitation of the achieved results on the private markets, thus increasing the expected cost for the public buyer. In addition, it is fairly understandable that governments would like to stimulate innovation from national firms, which is made difficult by both the EU law and international trade agreements, that forbid State-aids.

In order to fill the gap, the EC has issued the Communication "Precommercial Procurement: Driving innovation to ensure sustainable high quality public services in Europe". ${ }^{21}$ The document sketches a suitable model for innovation-targeted strategic use of public procurement, compatible with both the EU law and the international trade agreements, such as the WTO Government Purchase Agreement.

\footnotetext{
${ }^{18}$ See Katz and Shapiro (1985).

${ }^{19}$ By pre-commercial solution it is meant the original development of a first product or service. The WTO Government Purchase Agreement (Art. XV) points out that this "may include limited production or supply in order to incorporate the results of field testing and to demonstrate that the product or service is suitable for production or supply in quantity to acceptable quality standards".

${ }^{20}$ EU Directive 2004/18, Art. 16.

${ }^{21}$ See the EU Communication 2007/799 on Pre-commercial procurement. This document is also based on a study commissioned by the EC, (National IST Directors Forum Working Group, 2006).
} 
The proposed approach is based on two clearly distinct phases. ${ }^{22}$ The object of the first phase is the acquisition of R\&D services only. It basically consists of a sort of multi-stage "R\&D contest" ${ }^{\prime 23}$ aimed at developing a pre-commercial solution in response of a concrete need or problem. The model of this phase is based on (i) distinct competitive stages with sequential selection of a lower and lower number of projects, remunerated at each stage by with a cost-reimbursement approach; (ii) sharing of both risks and benefits of the R\&D between the buyer and the competitors - for instance, through careful allocation of the generated IPRs, (iii) avoiding State-aids. The second phase, in turn, is the "commercial" one, and consists in a "standard" procurement tendering procedure in order to acquire off-the-shelf products or services. Hence, it can take place in the frame of the procurement Directive. Of course, the results of the R\&D activity of the first phase can be embedded in the finally procured contract.

\subsubsection{Procurement for Innovation}

Beyond the direct procurement of innovative projects, the government is in a position to target its purchasing activity to stimulate production and diffusion of innovation in several other indirect ways. ${ }^{24}$

To this end, a possible strategy may concern the design of competitive tendering processes and, in particular, how requirements, requisites and specifications are set in tender documents. Let us consider the case of a public buyer procuring a product or service in order to satisfy specific needs and solve specific problems. If the object of the contract to be awarded is described in the tender documents in terms of performance requirements and functional specifications rather than in terms of product/service technical specifications or standards, the competitors have both more incentive and more leeway to research the most efficient solution to address the needs expressed in the tender documents and fulfill contract requirements. ${ }^{25,26}$

In some sense, the same idea is also at the basis of the competitive dialogue, a new negotiation tool introduced in the EU law by the 2004

\footnotetext{
${ }^{22}$ A more detailed description of the proposed model is provided by the European Commission (2007), in an accompanying document to the EU Communication 2007/799.

${ }^{23}$ Research contests and the adoption of auction mechanisms to select and reward the winners have been studied, among others, by Taylor (1995) and Fullerton et al. (2002). A simpler, less technical discussion is provided by Cabral et al. (2006).

${ }^{24}$ The interest of the EU for promoting innovation through public procurement is testified, for instance, in European Commission, (2005b), also known as the Wilkinson Report. For a more recent discussion, see EU Project OMC-PTP (2009).

${ }^{25}$ This strategy is also allowed by the EU Directive 2004/18.

${ }^{26}$ A more detailed discussion of functional specifications and their role in stimulating innovation is provided in European Commission (2005b).
} 
Directive. Actually, the competitive dialogue is explicitly aimed at dealing with complex projects which require a careful research and development of the best solution to address specific procurer's needs. Competitive dialogue is a flexible procedure which, while preserving competition between economic operators, also takes into account the need for the contracting authorities to discuss all aspects of the contract with each candidate. Though, competitive dialogue is not exempt from criticisms (Arrowsmith, 2006).

To be sure, government procurement is also able to foster diffusion of innovative products throughout the public administration. When the size of such purchases is not negligible with respect to the overall size of the market or in markets where network effects play an important role, standardization of publicly procured goods/services can affect the dominant standard on the market. ${ }^{27}$ The strategic adoption of standards in the tender documents to stimulate innovation has been tackled by the EC by the STEPPIN project that lead to the drafting of a Handbook of policy guidelines. $^{28}$ It should emphasized, however, that the role of standardization in fostering innovation is quite controversial (Allen and Sriram, 2000).

\subsection{Centralized Procurement and Sustainability}

The financial component of value for money ought not be simply the purchasing price of a certain good/service (or even a civil work), rather the life-cycle cost (LCC), that includes both operating costs (e.g., energy, spares and maintenance) and end-of-life costs (e.g., decommissioning and removal). Stretching the time horizon for evaluating the financial dimension(s) of the value for money may have at least two benefits: i) it makes all financial components more visible and transparent, thus allowing buyers to trade-off, say, a higher purchasing cost today with a lower maintenance cost tomorrow; ii) expenditures at different stages of the life-cycle are emphasized, thus allowing public buyers to better plan whenever admissible by public accounting rules - budgetary predictions over several years.

${ }^{27}$ On relationships between standardization and network effects, a seminal contribution is Katz and Shapiro (1985). See also Besen and Farrell (1994) and Gandal (2002).

${ }^{28} \mathrm{~A}$ web-based version of the Steppin Handbook (2008) is available at http://standards.eu-innova.org/Pages/Steppin/Tools.aspx. A more comprehensive survey of the project is carried out by Apostol (2010). 
The LCC approach for implementing Green Public Procurement (GPP) has become in recent years one of the pillars of the European Commission's policy guidelines on public procurement. ${ }^{29}$

The broad objective of GPP is to design procurement strategies so as to minimize the amount of negative externalities on the environment. To better clarify this objective, it would be useful to mention some of the main findings of a research project - called RELIEF ${ }^{30}$ - co-funded by the EC, aiming at scientifically assessing the potential environmental benefits of EU-wide green procurement strategies. The findings concluded that:

- If all public authorities across the EU demanded green electricity, this would save the equivalent of 60 million tonnes of $\mathrm{CO} 2$, which is equivalent to $18 \%$ of the EU's greenhouse gas reduction commitment under the Kyoto Protocol. Nearly the same saving could be achieved if public authorities opted for buildings of high environmental quality.

- If all public authorities across the EU were to require more energyefficient computers, and this led the whole market to move in that direction, this would result in 830.000 tonnes of $\mathrm{CO} 2$ savings.

- If all European public authorities opted for efficient toilets and taps in their buildings, this would reduce water consumption by 200 million tonnes (equivalent to $0.6 \%$ of total household consumption in the EU).

The findings just mentioned emphasize "social" benefits stemming from green procurement, that is, the reduction of negative externalities from lower $\mathrm{CO} 2$ and pollutants emissions or lower consumption of raw materials. Thus, under normal circumstances, procurement strategies with a positive (resp., negative) environmental impact are typically cases of positive (resp., negative) externalities. GPP strategies may also generate private benefits, accruing directly to the public buyer. In most cases they arise from future savings due, for instance, to lower consumption of energy or water or from lower waste or disposal cost. But sometimes there might be concerns about better or healthier working conditions for the employees, which might also result in lower risks for the employer.

Some remarks are useful about this distinction. First of all, the two effects often coexist and are strongly related. Energy efficiency solutions, for instance, allow lower consumption yielding both lower operating expenditures for the buyer and lower pollution for the environment. In general, green purchasing accruing a private benefit for the buyer causes a

${ }^{29}$ Plenty of information about the EU approach to GPP is available at http://ec.europa.eu/environment/gpp/index_en.htm. In particular, see European Commission (2004).

${ }^{30}$ For more on the RELIEF project see the website (ICLEI, n.d.) www.iclei-europe.org . 
positive externality for the environment as well. The converse is not always true, though. In some cases, green products might leave unchanged or even decrease the direct utility of the procurer. Consider, for instance, the use of recycled paper for printers, which has a lower environmental impact than bleached paper but brings no advantage to the users, either in terms of quality (which, on the contrary, may be perceived as lower) or in terms of costs (which may be higher). Another example is the procurement of products with low environmental impact at the production phase, which may result more costly without providing the user with any additional benefit.

The EC's guidelines seem to neglect this important distinction which, in turn, is likely to strongly affect the buyers' willingness to pay for green products. In fact, it is clear that any buyer - be it either public or private buyer - might be willing to pay a higher purchasing price against future savings on usage and disposal. Indeed, private benefits can be fully internalised. But this is not the case for externalities: a buyer caring about her own utility only, will not be willing to pay an higher price in order to bring a positive externality (or avoid a negative one) to the society. Many in fact believe - or simply wishfully think - that a public administration should have strong social responsibility and so care about the environment in the interest of the whole society. Nevertheless, it is plausible that the preferences of any public administration and, more in particular, of public officials and policy makers are related to many complex factors that could prevail on the environmental impact of their decisions. As an example, one could just consider the case of many Countries reluctant to sign international agreements about global warming reduction. At a lower level, a local municipality might be scarcely interested in investing money in energy efficiency projects, because the pay-back period may exceed the political cycle, so it might prefer to allocate resources to different projects.

The question is then to what extent some form of demand aggregation would be beneficial in consistently pursing GPP strategies. First, any "small" public buyer - say, a local municipality - reaps only a tiny fraction of the overall reduction of negative externalities (CO2), so it is likely to be affected by a standard free-riding problem, that is, to underestimate the value it attaches to lower pollution. ${ }^{31}$ When demand of several public agencies is aggregated - for instance, by means of a central purchasing body - the overall value of lower externalities can be internalized by a

\footnotetext{
${ }^{31}$ In fact, it should be noticed that some governments provide the contracting authorities with (either indicative or mandatory) values for the discount rates that should be adopted to evaluate and compare the return of investments on sustainable procurement initiatives.
} 
single (framework) contract awarded on behalf of several final users. Demand aggregation may then become an effective tool to (almost) fully internalize social benefits.

Secondly, demand aggregation could come into play as an important incentive for the economic operators to pursue innovation focused on environmental-friendly products and processes. In this sense, all the considerations carried out about the role of centralized procurement to stimulate innovation hold altogether.

The third potential advantage of centralized strategy originates from the inability of a single public buyer to optimally solve the intertemporal budget planning. This stems from a couple of reasons, at least.

Firstly, it should be noticed that solving the intertemporal trade-off between cheaper investments "today" and lower operating cost and/or benefit for the environment "tomorrow" (i) does necessarily require a LCC analysis which, in turn, (ii) implies to set the "optimal" discount rate to weight and value future benefits from GPP and estimate the return of related investments. All this requires a specialized know how that "small" public agencies are likely not to have access to. Secondly, it seems reasonable to assume a central purchasing agency to have a longer time horizon due, for instance, to the political cycle considerations mentioned above. This, in turn, implies that the discount rate set by a central agency may result closer to the "socially optimal" discount rate.

Of course, defining the socially optimal discount rate is not easy at all ${ }^{32}$, also because here the distinction between private benefit and positive externalities (discussed above) plays an important role too.

Indeed, a distinction should be made between the standard discount factor (also named "private rate") and the "social" one, the difference being that while the first just considers the market remuneration for monetary investments over the time, the second one also takes into account the social impact that this investment could weigh on social welfare.

A fair amount of literature exists dealing with the concept of social discount rates and their relations with global warming and climate change. Seminal papers are by Dasgupta et al. (1999) and Dasgupta $(2008)^{33}$. The main idea underlying these papers is that, when a public authority faces an intertemporal welfare maximization, it might be extremely hard today to evaluate environmental risks in the distant future.

\footnotetext{
${ }^{32}$ Some governments or other institutions recommend (a range of) values for the discount rate to be used to estimate the net present value of GPP initiatives. For instance, the UK government suggests $3.5 \%$, as shown in (UK, HM Treasury, 2003). Some considerations are also provided by the OECD (2003) and by the Öko Institut e.V. (2007).

${ }^{33}$ For further references on intertemporal public choice and climate change, see also Schelling (1992), Cowen and Parfit (1992) and Nordhaus (1994).
} 
Dasgupta et al. (1999) argue that social discount rates have to be estimated by considering the institutional setting within which social cost benefit analysis is assumed to be undertaken. These rates are not necessarily positive, but even negative if investments imply environmental pollution (in any case, these rates would be strictly lower than the private rates). In the path of the climate change, Dasgupta (2008) maintains that, once one realizes that social discount rates are not observables and ethical primitives, they must be derived by accounting from economic forecasts and society's conception of distributive justice on intertemporal allocation of goods and services.

\section{Designing Centralized Procurement Through Two- stage Processes}

Strong centralization can normally be implemented at some cost, mainly the risk of "loose tailoring" of public contracts to purchasing units' needs. Several reasons may explain the so-called "demand heterogeneity": physical location (e.g., schools located on high mountains rather than in town, leading to different transportation costs); nature of the public service provided (Police Departments will put by far a stronger importance on cars' maintenance than Inland Revenue); different bundles of the same commodities (in a contract for food raw materials, different public agencies may need vegetables and meat in different proportions); different customizations of the same products or need for different optional services; or simply intrinsic characteristics as buying entities (timeliness of payments, managerial skills in enforcing public contracts etc.). Heterogeneity may simply stem from purchases taking place at different points in time. For instance, technological obsolescence does affect, ceteris paribus, the performance of a laptop. Consequently, purchase orders of laptops belonging to the same broad family turn out to concern with substantially different commodities when the speed of the processor becomes higher and higher over time due to hardware evolution.

In order to reconcile demand aggregation, contract tailoring and process streamlining, a flexible two-stage procedure could be designed whereby:

- At the first stage, all or part of the terms of the contracts to be awarded are defined (framework agreement or master contract).

- At the second stage (call-off), the actual contracts are awarded (specific contracts or purchasing orders).

Without the ambition of being exhaustive, a two stage process may result useful in two kind of situations: repeated purchases by a single public agency and single/multiple purchases by different public agencies. 
In both circumstances, the presence of a procurement agency may be envisaged, acting on behalf of other public authorities to conclude the framework agreement, that is, to draft the master contract.

\subsection{What are Framework Agreements?}

Framework agreements (henceforth, FAs) are anticipated arrangements for the delivery of goods and services over a certain period of time. According to both international practices and regulation, three broad definitions of FAs can be identified:

- $\quad$ The European Union, in the procurement 2004 Directive, (EU) defines FAs as "agreements between one/more contracting agencies and economic operator(s) ... to establish the terms governing contracts to be awarded during a given period ... with regard to price and ... the quantities envisaged."

- $\quad$ The United States of America have adopted different options such as: Government-Wide Acquisition Contracts (GWAC), Indefinite Delivery/Indefinite Quantity (IDIQ) contracts and Multiple Award Schedules (MAS) that imply multiple standing contracts with subsequent competition for task or delivery orders.

- The United Nations Commission on International Trade Law (UNCITRAL) defines a FA as a transaction to secure the supply of a product or service over a period of time (periodic/recurrent purchase arrangement, periodic requirements arrangement, periodic supply vehicle).

The three families are linked by two common traits: the aggregation of demand for goods and services to be delivered/provided at different moments in time; the adoption of a two-stage procurement process. ${ }^{35}$ In the following two sections, we will emphasize the potential benefits and risks from aggregating (not necessarily homogeneous) public demands, possibly originating from different purchasing units - be them offices within the same Department/Ministry rather than contracting authorities scattered over a certain territory - and those arising from a two-stage procurement process.

In Europe, the evolution of regulation on public procurement in the last few years - together with a series of interpretations ${ }^{36}$ of the same regulation issued by the European Commission itself - has led

\footnotetext{
${ }^{34}$ EU Directive 2004/18. The definition of FA is provided in the Art. 1(5). Art. 32 is entirely devoted to FAs.

${ }^{35} \mathrm{An}$ insightful analysis of differences and common traits between the adoption of framework arrangements in Europe and in the US is provided by Yukins (2008).

${ }^{36}$ See, in particular, the Explanatory Note provided by the European Commission (2005a).
} 
procurement officers and scholars alike to classify FAs according two major dimensions: i) the degree of completeness of the master contract; and ii) the number of economic operators with whom a FA is concluded. This would almost naturally lead to four classes of FAs as described in Table 1.

Table 1 - Classification of Framework Agreements

- Complete (all conditions established in the master contract)

- Single award (one economic operator)

- Complete (all conditions established in the master contract)

- Multiple award (more than one economic operator, at least 3 in Europe)
- Incomplete (not all conditions established in the master contract)

- Single award (one economic operator)

- Incomplete (not all conditions established in the master contract)

- Multiple award (more than one economic operator, at least 3 in Europe)

One immediate consequence of the above classification is that one is led to believe that whether a FA is complete or incomplete is hardwired in the master contract, that is, a FA is crafted either complete or incomplete. There exist, however, a more flexible approach to the design of the master contract which is currently advocated by the Office of Government Commerce $^{37}$ in the UK whereby the FA may establish all the "core" conditions at the first stage - so as to make purchase orders immediately available - although some contractual clauses may be modified at a later stage where competition s reopened. Next sections will discuss more in details the most common classes of FAs.

\subsection{The Benchmark Case of Frame Contracts}

It is worth starting our analysis with the case of a FA concluded with one economic operator and all conditions established in the master contract. This kind of FA, also known as "frame contract" (FC) is very close to the centralized procurement strategy implemented by the Italian Public Procurement Agency (Consip S.p.A.) within the program of rationalization of public spending ${ }^{38}$. Public agencies, both at a central and

\footnotetext{
${ }^{37}$ This approach is presented, for instance, in the Guidance on Framework Agreements (OGC, 2006). Available at

http://www.ogc.gov.uk/documents/guide_20framework_agreements.pdf.

${ }^{38}$ For further information on Consip and its public procurement strategies, see www.consip.it and Broggi (2009).
} 
local level, are entitled to make purchase orders from the FC awarded by the central procurement agency ${ }^{39}$.

The main feature of a FC is that quality-price competition is entirely concentrated in the first stage, whereas the second stage, at which the specific contracts are awarded, is simply reduced to issuing of purchase orders. Hence, the main advantages of centralization, namely increased degree of competition and process streamlining, may deploy their full potential for the following reasons.

Firstly, bundling separate procurement strategies into a single process will avoid repeating the same tasks and allow specialized personnel to check the tender documents more carefully, thus considerably reducing the risk of litigation at any stage of the procurement cycle. There exists, however, an additional benefit that normally goes unnoticed, namely the "standardization of the procurement language", since different purchasing needs will be satisfied by relying on the same procedure. Standardization helps reduce barriers to entry into the procurement market, as firms will save on resources employed to check the differences among procurement strategies adopted by distinct contracting authorities, even if the latter end up purchasing similar commodities.

Secondly, if several purchase orders (for commodities) are squeezed into the same contract, the contractor(s) is (are) likely to operate at much lower unit costs than the level that would be attainable when the overall value is split in many separate contracts. As mentioned in section 2.1, if the economies of scale and/or the higher bargaining power of the central procurement agency more than compensate for the potentially lower number of competing firms - due to more stringent economic/financial participation requirements - a centralized FC may trigger tighter competition and generate sizeable savings.

One noticeable exception to the above line of reasoning may arise when the master contract does not refer to commodities such as gasoline, computers, or printers; rather, to services that require some specialized amount of human capital. This is the case of "general purpose" FCs for IT services awarded by Consip on behalf of the Italian Ministry of Economy and Finance (MEF), including a large variety of activities, from simple maintenance to developments of new applications, from software customization to integration of complex systems. Quality proposals consist in providing effective and flexible teams of professionals and technological solutions to best fit the various needs of the MEF. The

\footnotetext{
${ }^{39}$ For instance, frame contracts awarded by Consip set both price and all the contractual clauses (but quantity and time of delivery of the single purchase orders). In addition, they never guarantee a minimum volume of purchases, rather establish an upper bound only. Thus the contractor bears all the uncertainty on the discrepancy between estimated and realized demand.
} 
contractor is required to modify its working team to undertake a variety of tasks that will be precisely defined only after the "master" contract has been awarded. A risk then arises that the contract may resemble a sort of "Pandora's box" of heterogeneous services, generating high uncertainty when firms have to submit financial/technical proposals.

Nevertheless, by its very nature, any (centralized) FC also risks to become an inflexible purchasing tool that may not fit many public agencies' needs. So the higher the demand heterogeneity the more difficult to squeeze several purchase orders into the same FC. If demand aggregation is a bottom-up process, that is, if several public agencies explicitly delegate a centralized procurement agency (in fact, one of the public agencies may operate as such) then it should in principle be possible to determine in advance to what extent the same FC meets the needs of at least a fraction of final demand. Should demand aggregation be designed as a top-down process, that is, should a centralized procurement agency be entrusted with the mission of awarding FCs on behalf of public agencies, then some of the positive effects of centralization may be jeopardized if public agencies are not mandated to purchase through the same FC. In other words, if public agencies do have an "outside option" to buy by themselves, competing firms run the risk that realized demand ends up being much lower than the pre-award conjectured level. High uncertainty is likely to raise submitted prices thus hampering the positive effect on savings due to firms exploiting economies of scale.

Another major drawback of FCs originates from the risk of "adverse selection." It is well known since Akerlof's seminal contribution (Akerlof, 1970) that trade in markets may break down when buyers cannot distinguish between high and low quality goods. Since buyers' willingness to pay does not exceed the value of the "average quality" product, only sellers of low quality will be willing to trade. Anticipating this, rational buyers may refrain from purchasing altogether. A similar phenomenon may arise in centralized "FCs". Since the same contractual clauses apply to all subsequent purchases, and public agencies may differ from each other with respect to one or more dimensions that ultimately affect contractor's realized profit, the latter are bound to make offers based on the "public agencies' average profile". Consequently, "bad" public agencies are more likely to issue purchase orders.

Let us see the potentially harmful consequences of adverse selection in a stylized FC for car insurance. Suppose that public agencies differ with respect to the risk of accident of employees using cars for accomplishing their duties. Public agency " $G$ " displays good accident records (low-risk), whereas public agency " $\mathrm{B}$ " displays very poor records (high-risk). Defining $p_{G}$ and $p_{B}$ the insurance premiums for low-risk and high-risk 
drivers respectively, an insurance company would set $p_{G}<p_{B}$ if it were able to make two separate offers. Requiring all conditions to be fixed, a FC would determine only one insurance premium. How would firms set the average insurance premium $p_{A}$ ? The competitive level of $p_{A}$ is likely to depend, ceteris paribus, on whether the use of the FC is mandatory. If this is the case, and firms have sensible conjectures about the fraction of highrisk public agencies, say, $60 \%$, then competition would drive the premium to a level of $p_{A}=0.6 p_{B}+0.4 p_{G}$. The resulting purchase orders give rise to social inefficiency since high-risk (resp. low-risk) agencies are paying too a low (resp. high-risk) insurance premium than the ones that would emerge from insurance companies negotiating directly and separately with public agencies. If, instead, the use of the FC is on a voluntary basis, then any "average" insurance premium $p_{A}$ such that $p_{G}<p_{A}<p_{B}$, would cause lowrisk public agencies to look for a better outside option. Rational profitmaximizing firms will anticipate that only high-risk public agencies will purchase through the FC, thereby setting $p_{A}=p_{B}$.

\subsection{The Multi-award Incomplete Framework Agreements}

\subsubsection{The Main Goal of Incomplete Framework Agreements}

Despite the formal classification into different "families" sketched in section 4.1, most public procurement practitioners use to think about FAs by implicitly referring to the "incomplete" FAs concluded with more than one economic operator. It is unsurprising, then, that they are identified by the Explanatory Note $^{40}$ of the Directive issued by the European Commission as FAs strictu sensu.

As discussed in the previous section, frame contracts allow public buyer(s) to reap most of the "classic" benefits of centralization, namely via tough competition, efficient use of specialization and knowledge sharing among the procurement officials, and minimization of the effort and process cost of the purchasing unit(s). On the other hand, "simple" purchasing contracts concluded through distinct and autonomous awarding procedures, while giving up such benefits, provide the contracting authorities with the maximum flexibility and possibility of customization and reduce the uncertainty faced by the competitors. Ideally, simple contracts also ensure allocative efficiency, in the sense that each contract will likely be served by the supplier who is the most efficient to do it.

In this perspective, which ranks the different procurement strategies on the basis of the degree of standardization (or centralization), multi-award "incomplete" FAs (or FAs strictu sensu) lay somewhere in between FCs

\footnotetext{
${ }^{40}$ See note 36 .
} 
and simple contracts (Figure 1). This suggests that their main purpose should be to address the trade-off between demand aggregation and process efficiency on the one hand and customization, flexibility and allocative efficiency on the other one ${ }^{41}$. In other words, the main goal of incomplete FAs is to streamline the process for repeated purchases by providing a large amount of the overall required effort in the first selection round, while leaving some space for customization and further competition at the second stage, when the actual procurement needs arise and their specific features (quantities, delivery conditions, specific tasks to be undertaken, customizations requested) become better known.

Figure 1 - The Nature of Framework Agreements is Determined by the Main Features of the Two Sides of the Market

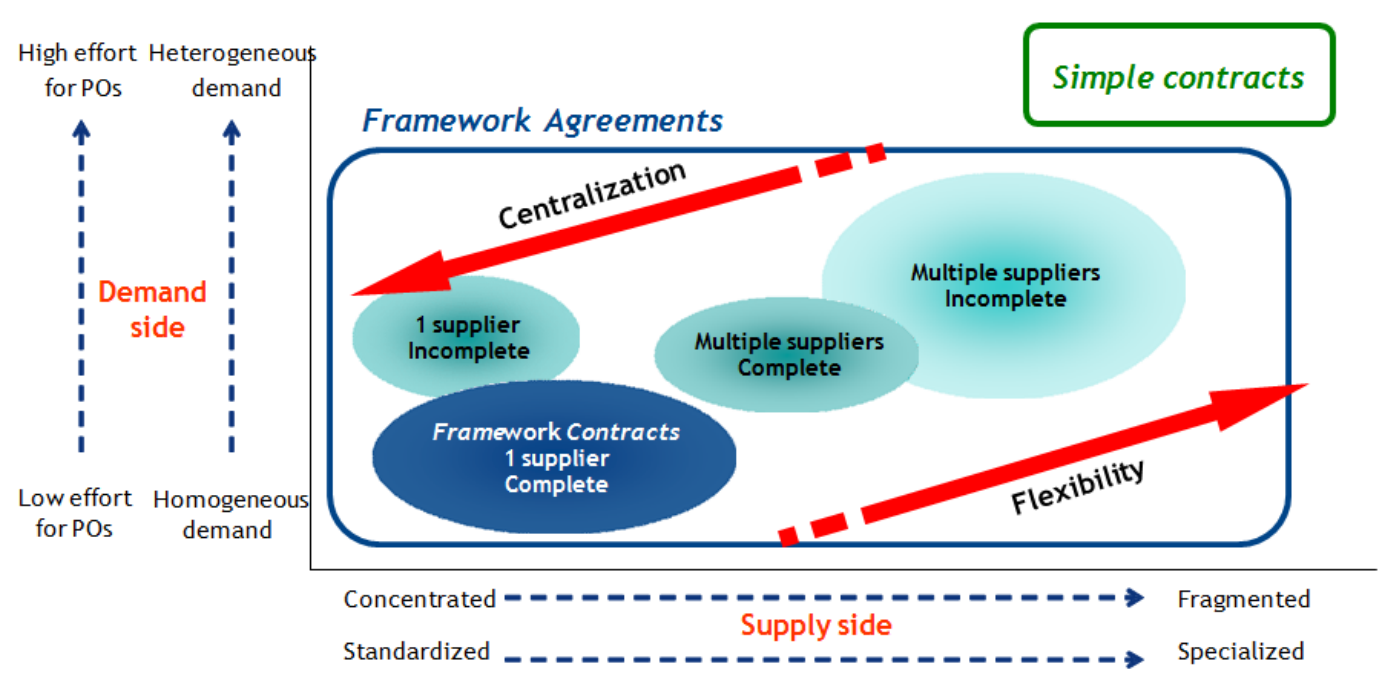

As mentioned above, such a mechanism typically turns out to be very useful in the case of a central purchasing agency concluding the agreement in order to define the basic qualitative features as well as upper-bound price conditions for contracts to be awarded by different and heterogeneous contracting authorities. This is the case, for instance, of the GSA Schedules in the US (accessible all US Federal Government agencies), of the FAs concluded by OGC Buying Solutions in the UK, and Hansel in Finland. In what follows, however, we will focus our attention to the case where the FA is concluded and all the specific contracts are awarded by one single contracting authority.

${ }^{41}$ The trade-off between competition and efficiency in incomplete FAs is analyzed more formally by Albano and Sparro (2008) in a stylized two-stage model with horizontal differentiation. 


\subsubsection{The Two-stage Competition}

If the needs and/or the preferences of the contracting authority are somehow unknown or heterogeneous with respect to relevant aspects of the contracts to be awarded, it this then optimal to let these aspects to be defined through a second round of selection (the call-off stage). When actual needs arise, so that the uncertainty about the exact object and characteristics of a single specific contract is sensibly reduced, the selection is reopened and the operators part of the agreement are asked to precise and/or complete their first-stage offer. Thus, unlike FCs, the twostage procurement process consists of two distinct rounds of competition.

In practice, let us consider the case of a process based on the Economically Most Advantageous Tender (EMAT) awarding criteria. In the most general case, at both stages offers are scored, ranked and selected on the basis of both price and technical sub-criteria, established in the tender documentation of the FA. Importantly, the offers submitted at the first stage cannot be substantially modified at the second stage ${ }^{42}$. A possible practical interpretation of this principle is that "core" or "basic" technical features of the supply/service have to be evaluated when concluding the FA and may not be successively modified. Competition can instead be reopened with respect to optional items/services, customizations or further improved qualitative features. As regards the financial offers, a commonly adopted rule is that prices submitted at the first stage can only be lowered at the call-off stage.

Such a mechanism yields several strategic implications. Firstly, the suppliers may want to submit their best offers since from the first stage only with respect to the features of the contract that cannot be successively changed. On the contrary, they will possibly avoid to compete too aggressively on price, so as to offer the highest price that allows them to be selected at the first stage. In fact, this could allow them to exploit possible (technical) competitive advantage at the second stage and keep their profit high. Secondly, it is possible that some competitors aim at entering the agreement in order to serve one (or a few) specific contract(s) only. This could induce them to submit a very aggressive bid at the first stage while restraining from participating in some of the second-round competitive tendering, thus distorting the first-stage competition and hampering the efficiency of the whole mechanism. Both these issues can

\footnotetext{
${ }^{42}$ In particular, the EU Directive 2004/18, in the Art. 32, states that "When awarding contracts based on a framework agreement, the parties may under no circumstances make substantial amendments to the terms laid down in that framework agreement". A possible rationale for this prescription is that substantial changes to the tenders at the call-off stage would represent a harmful distortion of the first-stage competition.
} 
be found even in a very simple modelling of FAs, like the one, based on the lowest price criterion, in Albano and Sparro (2008).

\subsubsection{Balancing Competition}

The main message of this discussion is that the degree of heterogeneity between (or the degree of uncertainty about) the specific contracts plays a crucial role in the incentives provided to the potential competitors. As a consequence, from the point of view of the public entity designing and implementing the FA, the main issue to address is how to balance the competition between the two stages. Spurring competition at the first stage, de facto pushes a FA to end up more similar to a FC. On the contrary, when competition for selecting the operators part of the agreement is loose, the call-offs tend to become similar to independently run competitive tenders. It is then worth to discuss the main aspects in the design of the whole process which affect the balance of competition between the two stages.

The first of such factors is the degree of completeness of the "master contract", i.e. the relative fraction of the clauses of the specific contracts which are set since from the first round of competition and cannot be modified at the call-off stage. The higher the number of clauses of the specific contracts defined at the first stage the lower the degree of competition at the second stage with respect to the first one.

In a FA awarded to the EMAT, when award criteria concern with a large share of the relevant terms of the supply contracts, then most of the overall score will be raffled at the first stage. Thus, at the call-off stage it will be harder, for the lower-ranked competitors who have entered the FA, to fill a gap of score arising from the first stage. This provides the suppliers to compete fiercely in order to enter the FA with a good score. On the other hand, an almost-complete master contract seems to be a suitable solution in cases where the degree of uncertainty or heterogeneity of the specific contracts is low, so limiting the risks from aggressive price bid since from the first stage.

From a normative point of view, the buyer should then focus the initial round of selection on all the aspects of the supply/service which are likely to be common to all the specific contracts. Of course, a more complete master contract will require more effort for concluding the FA (e.g., in carefully estimating the future needs and in evaluating the submitted offers) while it will streamline the call-off processes. Though, it will streamline call-off processes. Though, this will limit the degree of flexibility. In addition, it is worth emphasizing that a more complete master contract maximizes benefits from centralization and demand aggregation. As a consequence, from the discussion carried out in section 3 , it follows that, when issues like innovation or sustainability are relevant 
for the central purchasing agency concluding the FA, selection and award criteria related with such issues should also be adopted at the first, rather than at the second stage.

The second key aspect affecting the balance of competition is the number of economic operators part of the agreement. This number can be either exogenous (i.e., predetermined in the tender documents drafted by the contracting authority managing the first stage) or endogenous (i.e., the agreement can involve all the operators whose tenders reach a predetermined quality and/or price threshold) $)^{43}$. The first option can be considered more useful when tight first stage competition is pursued by the contracting authority, or when limiting the number of operators part of the agreement is important in order to reduce the effort needed to evaluate the submitted tenders at the second stage.

For a given number of potential competitors in the market, an exogenously fixed small number of winners induces higher competition at the first stage. Similarly, when the number of winners is endogenous, a similar effect is reached by setting higher the score threshold the competitors have to reach in order to enter the agreement. On the contrary, where the number of winners is high or the score threshold is low, competition will be focused on the call-off stage.

Also, the number of competitors in the agreement should be high when the expected number of specific contracts as well as their potential heterogeneity is high too. In fact, allowing a marginal supplier to enter the agreement should result useful to the extent that she does have concrete chances to be awarded with some contract (or, similarly, to put competitive pressure on the other operators in the agreement). Where this is not the case, an higher number of operators just lowers the competition at the first stage while making the management of the call-offs more cumbersome.

\subsubsection{Dealing with the Risk of Collusion ${ }^{44}$}

Upon concluding a FA, a "new market" will emerge, characterized by two salient features: i) the number of firms will be, in general, lower than the set of competing firms at the first stage; ii) firms in the FA know that

\footnotetext{
${ }^{43}$ This is typically the case for "open" Framework Agreements. A FA is open when new entrants can become part of the agreement at any time. Where this is the case, one cannot refer to a first round of competition, in the sense that true competition only takes place when awarding specific contracts. However, the present paper does not discuss this kind of FA. This is also because it lies outside the definition of FA provided by the EU Directive, which rather defines this mechanism Dynamic Purchasing System (adoptable for highly standardized commodities and through e-procurement platforms only).

${ }^{44}$ For a more general discussion on collusion in procurement markets, see Albano et al. (2006a).
} 
they will be competing over time for a stream of purchase orders. When the FA does not allow entry of new firms at a later stage ${ }^{45}$, the resulting market will bear a straightforward resemblance with an oligopolistic market in which firms may be tempted by adopting collusive strategies, thus softening competition to raise profit. Coordination, whether explicit or tacit, is both tempting and feasible since firms interact over time. In oligopolistic markets it typically takes a rather simple form. Firms set a high price and keep it stable over time only if no-one undercuts its rivals at any point in time. Cheating is normally deterred by the threat of a possibly ever-lasting price war.

In what follows, we will emphasize how the design of the FA and the stream of call-offs may increase the risk of collusion among firms.

The sequence of call-offs could, in principle, be assimilated to a public contract split into several lots, the difference being that lots are awarded at different points in time. For a given number of firms in the FA and for a given overall value of the latter, the higher the number of call-offs the higher the risk of collusion since there will be a higher number of "piesharing" arrangements to sustain a collusive scheme. One countermeasure would consist, whenever compatible with final demand, in lowering the number of call-offs (that is, reducing the frequency of interaction) by increasing the value of each call-off. This would reduce the number of potentially feasible collusive allocations. However, firms would be required to have higher financial/economic capacities, which would, in principle, reduce the number of competitors in the FA, thus making collusion more likely.

When deciding whether to adhere to a collusive strategy, each firm needs to evaluate the net benefits from current deviations - namely, shortrun profit minus the expected cost arising from other firms' punishing strategies - against the present value of benefits from cooperation. The latter depends crucially on firms' ability to predict as precisely as possible the stream of call-offs. The more predictable the stream of call-offs the more confident firms will be on "how much collusion is worth". Consequently, preventing collusion might require not announcing in advance the precise stream of purchase orders that will take place in the FA.

\section{Conclusions}

The choice of the "optimal" degree of centralization in procurement is relevant both to private as well as public organizations. Unlike the former, however, the latter has to design procurement strategies by fulfilling a

${ }^{45}$ This is in principle only feasible in a Dynamic Purchasing System. 
higher number of requirements mainly due to legal constraints, to the nature of the services provided by public organizations and by low-power incentive constraints for procurement officers (and, more generally, for civil servants). Moreover, as we have emphasized in the first part of the current work, public procurement is being advocated as a potentially effective tool to promote other socially valuable goals such as innovation in markets and sustainable development.

It then comes as no surprise that public procurement raises a variety of issues attracting scholars from different fields such as economics, law, computer science and operations research. Furthermore, casual observation seems to confirm that the practice of public procurement seems to be way ahead of research. This is in itself good news for academics since several puzzles are waiting to become full-fledged research programs. While resisting to the temptation of suggesting "avenues" for future research, we wish to point to three, among the most compelling, lines of investigations.

Firstly, international trade agreements (e.g. WTO) are increasingly recognizing the crucial role of public procurement regulation to open up local markets to international competition, thus creating equal access to procurement markets to both local and foreign firms. However, it is also argued that discriminatory procurement policies seem to be crucial for exploiting public procurement innovative potential. So, how to reconcile general principles of fairness and equality of treatment with the "need" of discrimination?

Secondly, most economists tend to overemphasize the relevance of public procurement competitive tendering design. The simple reason being that the competitive phase can be thought of as an auction, so the machinery developed by auction theorists in the last 30 years apply almost straightforwardly. Unfortunately, this is far from being the case. Many procurement contracts specify lots of technical and financial aspects, renegotiation is frequently observed - especially in civil works - while some contingencies remain unregulated by contract clauses. This leads sometimes to a high complexity of the contract management phase that feeds back into the competitive phase due to the repeated nature of procurement. Most of the relevant problems in public procurement would remain unquestioned if research were to focus almost exclusively on the competitive tendering aspect.

Thirdly, and perhaps most urgently, a more comprehensive and analytical approach to public procurement performance measures is in order. As policy guideline wiggle from value for money to social value for money, it becomes increasingly difficult to agree on reliable performance indicators, thus increasing the risk of leaving the assessment of public procurement strategies to merely subjective measures. 


\section{References}

Akerlof, G. (1970). The Market for 'Lemons': Quality Uncertainty and the Market Mechanism. Quarterly Journal of Economics, 84 (3), 488-500. doi:10.2307/1879431

Albano, G.L., Buccirossi, P., Spagnolo, G., \& Zanza, M. (2006a). Preventing Collusion in Public Procurement. In N., Dimitri, G., Piga, G., Spagnolo, (Eds.), Handbook of Procurement (pp. 347-380). Cambridge, UK: Cambridge University Press. doi:10.1017/CBO9780511492556.015

Albano, G.L., Calzolari, G., Dini, F., Iossa, E., \& Spagnolo, G. (2006b). Procurement Contracting Strategies. In N., Dimitri, G., Piga, G., Spagnolo (Eds.), Handbook of Procurement (pp. 82-120). Cambridge, UK: Cambridge University Press. doi:10.1017/CBO9780511492556.005

Albano, G.L., Spagnolo, G., \& Zanza, M. (2009). Regulating Joint Bidding in Public Procurement. Journal of Competition Law and Economics, 5 (2), 335-360. doi:10.1093/joclec/nhn022

Albano, G.L., \& Sparro, M. (2008). A Simple Model of Framework Agreements: Competition and Efficiency. Journal of Public Procurement, 8 (3), 356-378.

Allen, R., \& Sriram, R. (2000). The Role of Standards in Innovation. Technological Forecasting and Social Change, 64 (2-3), 171-181. doi:10.1016/S0040-1625(99)00104-3

Anton, J.J., \& Yao, D.A. (1989). Split Awards, Procurement and Innovation. RAND Journal of Economics, 20 (4), 538-552. doi:10.2307/2555732

Apostol, R. (2010). Formal European Standards in Public Procurement: A Strategic Tool to Support Innovation. Public Procurement Law Review, 2, 57-72.

Arrow, K. (1962). Economic Welfare and the Allocation of Resources for Invention. In R., Nelson (Ed.), The Rate and Direction of Inventive Activity: Economic and Social Factors (pp. 609-625). Princeton, NJ: Princeton University Press.

Arrowsmith, S.L. (2006). Competitive Dialogue and Negotiated Procedure, and Framework Agreements. In The EC's Consolidated Directives on Public Procurement. Stockholm, Sweden.

Besen S.M., \& Farrel J. (1994). Choosing How to Compete: Strategies and Tactics in the Standardization. Journal of Economic Perspectives, 8 (2), 117131.

Boldrin, M., \& Levine, D.K. (2005). The Economics of Ideas and Intellectual Property. Staff Report 357, Federal Reserve Bank of Minneapolis. 
Bolton, P., \& Dewatripont, M. (2004). Contract Theory. Cambridge, MA: MIT Press.

Broggi, D. (2009). Consip: The Value of an Experience. Theory and Practice Between e-Procurement and e- Government. Milano: Franco Angeli.

Cabral, L.M.B., Cozzi, G., Denicolò, V., Spagnolo, G., \& Zanza, M. (2006). Procuring Innovation. In N., Dimitri, G., Piga, G., Spagnolo (Eds.), Handbook of Procurement (pp. 347-380). Cambridge, UK: Cambridge University Press. doi:10.1017/CBO9780511492556.020

Carpineti, L., Piga, G., \& Zanza, M. (2006). The Variety of Procurement Practice: Evidence from Public Procurement. In N., Dimitri, G., Piga, G., Spagnolo (Eds.), Handbook of Procurement (pp. 14-46). Cambridge, UK: Cambridge University Press. doi:10.1017/CBO9780511492556.003

Cowen, T., \& Parfit, D. (1992). Against the Social Discount Rate. In P., Laslett, \& J.S., Fishkin (Eds.), Justice Between Age Groups and Generations (pp. 144-161). New Haven: Yale University Press.

Dalpé, R. (1994). Effects of Government Procurement on Industrial Innovation. Technology in Society, 16 (1), 65-83. doi:10.1016/0160791X(94)90021-3

Dasgupta, P., Maler, K.G., \& Barrett, S. (1999). Intergenerational Equity, Social Discount Rates, and Global Warming. In P.R., Portney, \& J.P., Weyant (Eds.), Discounting and Intergenerational Equity (pp. 51-77). Washington DC: Resources for the Future.

Dasgupta, P. (2008). Discounting Climate Change. Journal of Risk and Uncertainty, 37 (2-3), 141-169. doi:10.1007/s11166-008-9049-6

Dimitri, N., Dini, F., \& Piga, G. (2006a). When Should Procurement Be Centralized? In N., Dimitri, G., Piga, G., Spagnolo (Eds.), Handbook of Procurement (pp. 47-81). Cambridge, UK: Cambridge University Press. doi:10.1017/CBO9780511492556.004

Dimitri, N., Pacini, R., Pagnozzi, M., \& Spagnolo, G. (2006b). Multicontract Tendering Procedures and Package Bidding in Procurement. In N., Dimitri, G., Piga, G., Spagnolo (Eds.), Handbook of Procurement (pp. 193-219). Cambridge, UK: Cambridge University Press. doi:10.1017/CBO9780511492556.009

Dini, F., Pacini, R., \& Valletti, T. (2006). Scoring Rules. In N., Dimitri, G., Piga, G., Spagnolo (Eds.), Handbook of Procurement (pp. 293-321). Cambridge, UK: Cambridge University Press. doi:10.1017/CBO9780511492556.013

Edler, J., Tsipouri, L., Hommen, L., \& Rigby, J., (contacts in the project team), (2005). Innovation and Public Procurement. Review of Issues at Stake. Study for the European Commission (No ENTR/03/24). Fraunhofer Institute 
Systems and Innovation Research. Retrieved from http://cordis.europa.eu/innovation-policy/studies/full study.pdf

Edler, J., \& Georghiou, L. (2007). Public Procurement and Innovation Resurrecting the Demand Side. Research Policy, 36 (7), 949-963. doi:10.1016/j.respol.2007.03.003

EU Communication 2007/799. Communication from the Commission to the European Parliament, the Council, the European Economic and Social Committee and the Committee of the Regions - Pre-commercial Procurement: Driving Innovation to Ensure Sustainable High Quality Public Services in Europe.

EU Directive 2004/18. Directive 2004/18/EC of the European Parliament and of the Council of 31 March 2004 on the Coordination of Procedures for the Award of Public Works Contracts, Public Supply Contracts and Public Service Contracts.

EU Project. OMC-PTP. (2009). Exploring Public Procurement as a Strategic Innovation Policy Mix Instrument. Berlin: European Union.

European Commission. (1985). Completing the Internal Market: White Paper from the Commission to the European Council. Milan: European Union.

European Commission. (2003). The Internal Market: Ten Years Without Frontiers. Retrieved August 1, 2010, from http://ec.europa.eu/internal market/10years/docs/workingdoc/workingdoc_en.pdf

European Commission. (2004). Buying Green! An Handbook of Green Public Procurement. Belgium: European Union.

European Commission. (2005a). Explanatory Note - Framework Agreements Classic Directive. Retrieved August 1, 2010, from http://ec.europa.eu/ internal market/publicprocurement/docs/explan-notes/classic-dirframework_en.pdf

European Commission. (2005b). Public Procurement for Research and Innovation. Developing procurement practices favourable to $R \mathcal{E} D$ and innovation. Expert Group Report. Belgium: European Union.

European Commission. (2007). Example of a Possible Approach for Procuring RED Services Applying Risk-benefit Sharing at Market Conditions, i.e. Precommercial Procurement. Accompanying document to the EU Communication 2007/799.

Fullerton, R.L., Linster, B.G., \& McKee, M. (2002). Using Auctions to Reward Tournament Winners: Theory and Experimental Investigations. RAND Journal of Economics, 33 (I), 62-84. doi:10.2307/2696375

Gandal, N. (2002). Compatibility, Standardization, \& Network Effects: Some Policy Implications. Review of Economic Policy, 18 (1), 80-91. doi:10.1093/oxrep/18.1.80 
Geroski, P.A. (1990). Procurement Policy as a Tool of Industrial Policy. International Review of Applied Economics, 4 (2), 182-198. doi:10.1080/758523673

ICLEI, Local Government for Sustainability. (n.d.). RELIEF Project (20012003). European Research Project on Green Procurement. Environmental Relief Potential of Urban Action on Avoidance and Detoxification of Waste Streams Through Green Public Procurement. Retrieved August 1, 2010, from http://www.iclei-europe.org/productsactivities $/$ ?cmd=view\&aid=74

Katz, M.L., \& Shapiro, C. (1985). Network Externalities, Competition, and Compatibility. American Economic Review, 75 (3), 424-440.

Laffont, J., \& Tirole, J. (1993). A Theory of Incentives in Regulation and Procurement. Cambridge, MA: MIT Press.

Lewis, T.R., \& Yildirim, H. (2006). Managing Dynamic Procurement. In N., Dimitri, G., Piga, G., Spagnolo (Eds.), Handbook of Procurement (pp. 433445). Cambridge, UK: Cambridge University Press.

doi:10.1017/CBO9780511492556.018

Monti, M. (2010). A New Strategy for the Single Market at the Service of Europe's Economy and Society (Report to the President of the European Commission José Manuel Barroso). Retrieved August 1, 2010, from http://ec.europa.eu/internal_market/strategy/docs/monti_report_fin al $10 \quad 052010$ en.pdf

National IST Directors Forum Working Group. (2006). Pre-commercial Procurement of Innovation: a Missing Link in the Innovation Cycle. Report for the European Commission.

Nordhaus, W.D. (1994). Locational Competition and the Environment: Should Countries Harmonize Their Environmental Policies? Cowles Foundation Discussion Papers 1079, 261-287.

OECD. (2003). The Environmental Performance of Public Procurement. Issues of Policy Coherence. Paris, EU: The OECD Publishing.

OGC, Office of Government Commerce. (2006). Guidance on Framework Agreements in the New Procurement Regulations. Retrieved August 1, 2010, from http://www.ogc.gov.uk/documents/guide framework agreements.pdf.

Öko Institute e.V., Institute for Applied Ecology. (2007). Costs and Benefits of Green Public Procurement in Europe. Freidburg, Retrived August 2, 2010 from http://ec.europa.eu/environment/gpp/pdf/eu recommenda tions.pdf.

Schelling, T.C. (1992). Some Economics of Global Warming. American Economic Review, 82 (1), 1-14.

Scotchmer, S. (2004). Innovation and Incentives. Cambridge, MA: MIT Press. 
Steppin. (2008). STEPPIN Handbook. Supported by the European Commission under the Europe INNOVA initiative. Retrieved August 1, 2010, from http://standards.eu-innova.org/Pages/Steppin/Tools.aspx.

Taylor, C.R. (1995). Digging for Golden Carrots: an Analysis of Research Tournaments. American Economic Review, 85 (4), 872-890.

UK, HM Treasury. (2003). The Green Book. Appraisal and Evaluation in Central Government. London: UK Government.

Yukins, C.R. (2008). Are IDIQs Inefficient? Sharing Lessons with European Framework Contracting. Public Contract Law Journal, 37 (3), 545-568. 